\title{
Bottlenecks reduction using superconductors in high voltage transmission lines
}

\author{
Labib Daloub $^{1}$, Abdulatif Khrwat ${ }^{1}$, Rajeb Ibsaim $^{2}$ and Mohamed Regeai ${ }^{3}$ \\ ${ }^{1}$ University of Aljabel Algharbi, Gharian, Libya \\ ${ }^{2}$ University of Zawia, Zawia, Libya \\ ${ }^{3}$ College of Electronic Technology, Tripoli, Libya
}

\begin{abstract}
Energy flow bottlenecks in high voltage transmission lines known as congestions are one of the challenges facing power utilities in fast developing countries. Bottlenecks occur in selected power lines when transmission systems are operated at or beyond their transfer limits. In these cases, congestions result in preventing new power supply contracts, infeasibility in existing contracts, price spike and market power abuse. The "Superconductor Technology" in electric power transmission cables has been used as a solution to solve the problem of bottlenecks in energy transmission at high voltage underground cables and overhead lines. The increase in demand on power generation and transmission happening due to fast development and linked to the intensive usage of transmission network in certain points, which in turn, lead to often frequent congestion in getting the required power across to where it is needed. In this paper, a bottleneck in high voltage double overhead transmission line with Aluminum Conductor Steel Reinforced was modeled using conductor parameters and replaced by Gap-Type Superconductor to assess the benefit of upgrading to higher temperature superconductor and obtain higher current carrying capacity. This proved to reduce the high loading of traditional aluminum conductors and allow more power transfer over the line using superconductor within the same existing right-of-way, steel towers, insulators and fittings, thus reducing the upgrade cost of building new lines.
\end{abstract}

\section{Introduction}

Congestions has been exists in both new and traditional power systems but when it comes to managements, it is more complex in case of competitive power markets due to the unbundled nature which calls for more coordination. In the system under study "GECOL System" (General Electric Company of Libya), the case is different with its integrated structure and due to nonavailability of competitors and other utilities trading in power industry where GECOL dominating the market, in which congestion would relatively be an easier issue to handle. The issue is mainly related to the conductor temperature rise as the transmission lines are loaded which expand its length, thus increasing the line sag. Since in high transmission lines, the sag is calculated based on the clearance to earth surface, the line conductor loading is restricted to a certain degree of temperature to maintain the sag within the limits and therefore saving the line conductors from being melted [1]. In this research, a study was made to a heavily congestive overhead transmission line linking one of the most important peaking capacity plant of $4 \times 165 \mathrm{MW}$ known as TSPS (Tripoli South Power Station), with focal substation feeding the Greater Capital City of Tripoli from the south bond. The Feeding S/S situated at HKSS
(Hadba Khadra) district sum $18 \mathrm{~km}$ away from the generating plant [2].

The transmission line is $220 \mathrm{kV}$ double conductor Red-Wing ACSR, constructed sum 35 years ago when the line route was clear from any obstacles.

\section{Problem tackling}

A few limited scenarios can be recommended to tackle the issue of bottlenecks for power transmission to this high voltage line, however, most of them have advantages and disadvantages. These are as follows:

- By installing a simple cycle peaking capacity generating plant, which cannot be visible due to noise, fuel storage, fuel supply, etc.

- By installing a new overhead transmission line with similar specifications that goes all the way parallel with the existing line keeping the appropriate right of way which is no longer possible with route space unavailability.

- By upgrading to a bundle conductor which will require replacement of all fittings and accessories.

- By replacement of the traditional ACSR conductors with high temerature superconductor, in which is the most appropriate scenario as it extended in the same tower structures keeping the same insulations, fittings and accessories. 


\section{Congested line}

One of the bottlenecks experienced by Libyan power grid represented in $220 \mathrm{kV}$ double transmission line linking a main power injection points to the Libya Capital of Tripoli from the south bond, which is TSPS (Tripoli South Power Station) with HKD (Hadba Khadra) S/S, where the suffering of these 2 line from drastic load increase become very unacceptable, especially when disconnecting of other lines for conducting regular maintenance or routine check. In this paper, data on line constants, power loading and congestions were accumulated from the main utility GECOL (General Electricity Company of Libya) to model the 2 overhead lines of TSPS-HKD being the worst in overloading and one of the most important injection line to Greater Tripoli [3].

\section{Conventional conductors}

Most of power transmission lines in service utilize aluminum (AAC), aluminum-alloy (AAAC) or aluminum conductors steel-reinforced (ACSR) due to high conductivity of aluminum and low weight density, while steel is added in ACSR for extra strength to resist sags. The extruded aluminum strands used in conventional conductors carries all or most of the tension in the cable to provide adequate strength, however, heating a coldworked conductor may cause it to anneal. When aluminum anneals, the dislocations of its crystal structure begin to release, reducing the material's strength, thus, conductors aren't operated at temperatures that cause them to anneal. This is the basis of the operating temperature of most conductors. Moreover, aluminum conductors exhibit significant sag due to low elastic modulus.

Table 1. ACSR conductor parameters.

\begin{tabular}{|l|l|}
\hline Conductor type: & ACSR "Redwing" \\
\hline Sectional Area (A): & $\begin{array}{l}445.1 \mathrm{~mm}^{2} \text { (AL 30/3.92, } \\
\text { ST 19/2.35) }\end{array}$ \\
\hline Diameter (D): & $2.746 \mathrm{~cm}$ \\
\hline Weight (W): & $1.686 \mathrm{~kg} / \mathrm{m}$ \\
\hline Ultimate strength (UTL) & $15697 \mathrm{~kg}$ \\
\hline Modules Of Elasticity (E): & $8000 \quad \mathrm{~kg} / \mathrm{mm}^{2} \quad(78453$ \\
$\left.\mathrm{N} / \mathrm{mm}^{2}\right)$
\end{tabular}

AAC, AAAC, and ACSR cables are limited to operating temperatures of $90-100^{\circ} \mathrm{C}$. Above that limit, the alloyed metals which changed the nature of the metallic crystal increased its annealing temperature. Aluminum conductor will begin to anneal and lose strength, therefore, transmission lines with such type of cables are designed to operate below $60-75^{\circ} \mathrm{C}$ to limit their sag. The parameters of the existing conductor under study are shown in Table 1.

\section{Superconducting power lines}

High-temperature superconducting cables promise to revolutionize power transmission and distribution by providing lossless transmission of electrical energy. The development of superconductors with transition temperatures higher than the boiling point of liquid nitrogen has made the concept of superconducting power lines commercially feasible, at least for high-load applications [4]. One of the properties of a superconductor is that it will exclude magnetic fields, a phenomenon known as Meissner Effect [5]. It's all became after an observation made by $\mathrm{H}$. Kammerlingh Onnes, who states that If mercury is cooled below $4.2 \mathrm{~K}$, it loses all electric resistance and becomes a superconductor [6], $(0$ degrees Kelvin $=-273$ degrees Celsius). The observations were then made that other metals also exhibit zero resistivity below a certain critical temperature. The highest critical temperature was about $23 \mathrm{~K}$ until the discovery in 1986 of some high temperature superconductors. The 'high' temperatures are still low, the " $125 \mathrm{~K}$ is considered very high". With widespread use of superconducting technology in grid 'highways' energy consumption can be reduced by $5-7 \%$, which means an equivalent reduction in $\mathrm{Co} 2$ emissions from electricity generation. Alloys with $\mathrm{Zr}$ materials often listed as Thermal-resistant and Super-thermalresistant aluminum alloys (TAl and $\mathrm{ZTAl}$ ). These alloys are designed to operate at $150^{\circ} \mathrm{C}$ and $210^{\circ} \mathrm{C}$ respectively. (Super) Thermal-resistant Aluminum Alloy Cables, Steel Reinforced (Z) TACSR are formed similarly to ACSR, but utilize TAl or ZTAl rather than the typical workhardened aluminum conductor stranding. TAl and ZTAl materials are also used in GTASCR and ACCR cables [7].

\section{GAP-Type superconductor}

Gap-type superconductor is a stranded core surrounded by hollow cylinder of trap-wire, forming a gap between the core and the conductor which is filled with thermalresistant grease. $G(Z)$ TACSR utilizes a thermal-resistant aluminum alloy conductor, much like ACCR. The core is generally made of galvanized steel, the same as would be found in ACSS or ACSR. In the current study, the scenario of high temperature superconductor was considered for three types of materials (GTACSR, GZTACSR and ZTACIR). The current carrying capacity of various material types were compared and the GTACSR conductor was chosen as the best option for its high current carrying and was modeled in this study.

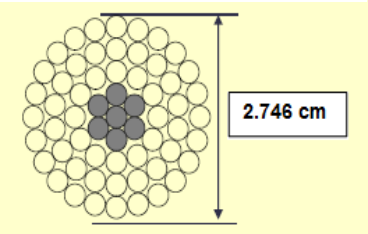

(a)

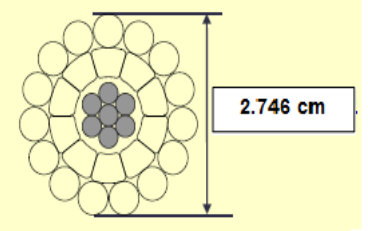

(b)
Figure 1. a) ACSR Conductor. b) GAP-Type Superconductor. 


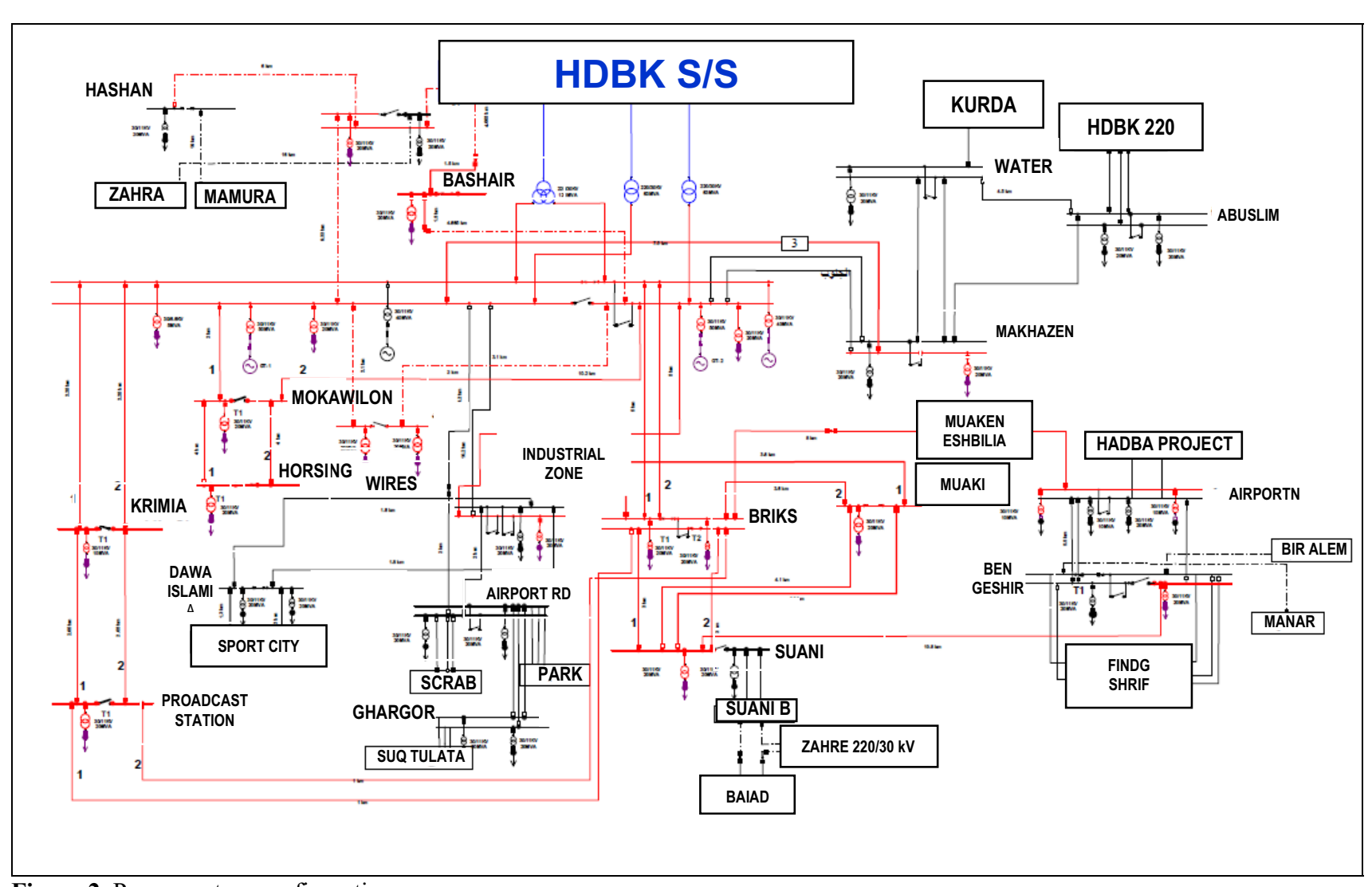

Figure 2. Power system configuration.

\section{The simulation model}

The simulation model was carried out using NEPLAN 260 Software to represent the actual situation of lines loading during daily peak hours and the solutions recommended to provide the most appropriate solution that can be used to overcome the problem of congestions.

The data used in the simulation is a real valid data collected through direct contact with Libyan power utility GECOL.
The congested transmission line was simulated with its existing situation and the results obtained clearly indicate the presence of congestion in the existing line. The line was again modeled by replacing the traditional ACSR by GTACSR superconductor and the obtained results proved and upgraded the transmission capacity of the line and cleared the bottleneck. The load flow result by the modeled transmission line is illustrated in the tables and figures above.

Table 2. Result of load flow of existing ACSR line.

\begin{tabular}{|c|c|c|c|c|c|c|c|c|c|c|c|c|c|c|c|}
\hline & From & To & P Loss & $\begin{array}{c}\mathrm{Q} \\
\text { Loss }\end{array}$ & $P \operatorname{lmp}$ & $\begin{array}{c}Q \\
\operatorname{Imp}\end{array}$ & $\begin{array}{c}P \\
\text { Gen }\end{array}$ & $\begin{array}{c}\text { Q } \\
\text { Load }\end{array}$ & $\begin{array}{c}P \\
\text { Load }\end{array}$ & $\begin{array}{c}\mathbf{Q} \\
\text { Load }\end{array}$ & $\begin{array}{l}\text { Gen } \\
\text { Cost }\end{array}$ & Qc Sunt & Ql Shunt & $\begin{array}{c}\mathbf{Q} \\
\text { Comp }\end{array}$ & $\begin{array}{c}\text { Iron } \\
\text { Losses }\end{array}$ \\
\hline & Area/Zone & ArealZone & MW & MVar & MW & MVar & MW & MNar & MW & MVar & Curr. Units & MVar & MVar & MVar & MW \\
\hline 1 & Netw ork & & 222.4 & -1149.4 & 6423 & -15.3 & $\begin{array}{l}5599 . \\
3\end{array}$ & -3079.3 & 5376.9 & -3408.6 & 0 & 0 & 366.5 & 0 & 0 \\
\hline 2 & Area 1 & & 222.4 & -1149.4 & 0 & 0 & $\begin{array}{l}5599 . \\
3\end{array}$ & -3079.3 & 5376.9 & -3408.6 & 0 & 0 & 366.5 & 1112.3 & 0 \\
\hline 3 & Zone 1 & & 38.52 & -6.95 & -1165.3 & 723.07 & 2013 & -807.31 & 809.13 & -557.9 & 0 & 0 & 366.5 & 114.15 & 0 \\
\hline 4 & Zone 2 & & 24.06 & -367.8 & 1747.5 & -1294.4 & 413 & -546.6 & 2136.4 & -1473.2 & 0 & 0 & 0 & 0 & 0 \\
\hline 5 & Zone 3 & & 91.52 & -157.3 & -908.8 & $9823^{-1}$ & 2461 & -1466.6 & 1460.6 & -1007.2 & 0 & 0 & & 680.19 & 0 \\
\hline $\begin{array}{l}6 \\
7\end{array}$ & $\begin{array}{l}\text { Zone } 4 \\
\text { Zone } 5\end{array}$ & & $\begin{array}{l}51.45 \\
16.81\end{array}$ & $\begin{array}{r}-531.2 \\
-86.19\end{array}$ & $\begin{array}{r}9522 \\
-625.5 \\
\end{array}$ & $\begin{array}{l}-508.6 \\
97.73\end{array}$ & $\begin{array}{l}70 \\
642.3\end{array}$ & $\begin{array}{r}-243.4 \\
-15.35\end{array}$ & $\begin{array}{l}970.7 \\
0\end{array}$ & $\begin{array}{l}-370.2 \\
0\end{array}$ & 0 & 0 & & $\begin{array}{l}149.3^{-} \\
168.6\end{array}$ & 0 \\
\hline 8 & & & & & & & & & & & 0 & 0 & & & 0 \\
\hline 9 & Ün & & $\mathrm{P}$ Loss L & QL & $\begin{array}{l}\mathrm{P} \text { Loss } \\
\mathrm{T}\end{array}$ & QLoss & & & & & & & & & \\
\hline 1 & $\mathrm{kV}$ & & MW & MVar & MW & MVar & & & & & & & & & \\
\hline 1 & 66 & & 0.001 & 0 & 0.202 & 4.35 & & & & & & & & & \\
\hline $\begin{array}{l}1 \\
1\end{array}$ & $\begin{array}{l}220 \\
400\end{array}$ & & $\begin{array}{l}143.97 \\
34.089\end{array}$ & $\begin{array}{l}-1425.2 \\
-880.47\end{array}$ & $\begin{array}{l}29.26 \\
14.847\end{array}$ & $\begin{array}{l}704.1 \\
447.79\end{array}$ & & & & & & & & & \\
\hline 1 & & & & & & & & & & & & & & & \\
\hline 1 & From & To & & & P Tie & QTie & $\begin{array}{l}\text { P Tie } \\
\text { Sc }\end{array}$ & & & & & & & & \\
\hline 1 & Area/Zone & ArealZone & & & MW & MVar & MW & & & & & & & & \\
\hline 1 & Zone 1 & Zone 2 & & & 1165.3 & -723.07 & & & & & & & & & \\
\hline 1 & Zone 2 & Zone 3 & & & -58216 & 571.4 & & & & & & & & & \\
\hline $\begin{array}{l}1 \\
2\end{array}$ & $\begin{array}{l}\text { Zone } 3 \\
\text { Zone } 3\end{array}$ & $\begin{array}{l}\text { Zone } 4 \\
\text { Zone } 5\end{array}$ & & & $\begin{array}{l}95219 \\
-625.5\end{array}$ & $\begin{array}{l}-508.64 \\
97.73\end{array}$ & & & & & & & & & \\
\hline 2 & & & & & & & & & & & & & & & \\
\hline
\end{tabular}


Table 3. Result of load flow simulation using GTACSR.

\begin{tabular}{|c|c|c|c|c|c|c|c|c|c|c|c|c|c|c|c|}
\hline & From & To & P Loss & $\begin{array}{c}\mathbf{Q} \\
\text { Loss }\end{array}$ & $P \operatorname{Imp}$ & $\underset{I m p}{Q}$ & $\begin{array}{c}P \\
\text { Gen }\end{array}$ & $\begin{array}{c}\mathbf{Q} \\
\text { Load }\end{array}$ & $\begin{array}{c}P \\
\text { Load }\end{array}$ & $\underset{\text { Load }}{\mathbf{Q}}$ & $\begin{array}{l}\text { Gen } \\
\text { Cost }\end{array}$ & Qc Sunt & Ql Shunt & $\begin{array}{c}\mathbf{Q} \\
\text { Comp }\end{array}$ & $\begin{array}{c}\text { Iron } \\
\text { Losses }\end{array}$ \\
\hline & Area/Zone & ArealZone & MW & MVar & MW & MVar & MW & MVar & MW & MVar & Curr. Units & MVar & MVar & MVar & MW \\
\hline 1 & Netw ork & & 225.7 & -1142.4 & 6423 & -15.35 & $\begin{array}{l}5599 . \\
3\end{array}$ & -3066.3 & 5373.5 & -3402.7 & 0 & 0 & 366.4 & 0 & 0 \\
\hline 2 & Area 1 & & 225.7 & -11424 & 0 & $0^{-}$ & 3599. & -3066.3 & 5373.6 & -3402.8 & 0 & 0 & 366.4 & 1112.4 & 0 \\
\hline 3 & Zone 1 & & 38.44 & -7.852 & $-165.9^{-1}$ & 713.17 & 2013 & .797 .47 & 808.62 & -556.9 & 0 & 0 & 366.4 & 114.12 & 0 \\
\hline 4 & Zone 2 & & 27.46 & -360.7 & 1749.5 & -12928 & 413 & -538.6 & 2136.1 & -1470.7 & 0 & 0 & 0 & 0 & 0 \\
\hline 5 & Zone 3 & & 91.59 & -156.02 & -909.7 & 990.2 & 2461 & -1471.4 & 1459.7 & -1005.5 & 0 & 0 & & 680.35 & 0 \\
\hline $\begin{array}{l}6 \\
7\end{array}$ & $\begin{array}{l}\text { Zone } 4 \\
\text { Zone } 5\end{array}$ & & $\begin{array}{l}51.41 \\
16.81\end{array}$ & $\begin{array}{l}-531.5 \\
-86.19\end{array}$ & $\begin{array}{l}951.5 \\
-625.5\end{array}$ & $\begin{array}{l}-508.3^{2} \\
97.72\end{array}$ & $\begin{array}{l}70 \\
642.3\end{array}$ & $\begin{array}{l}-243.4 \\
-15.35\end{array}$ & $\begin{array}{l}970.1 \\
0\end{array}$ & $\begin{array}{l}-369.6 \\
0\end{array}$ & 0 & $\begin{array}{l}0 \\
0\end{array}$ & $\begin{array}{l}0 \\
0\end{array}$ & $\begin{array}{l}149.4 \\
168.5\end{array}$ & 0 \\
\hline 8 & & & & & & & & & & & 0 & 0 & & & 0 \\
\hline 9 & Ün & & P'Loss L & QLoss & $\begin{array}{l}\mathrm{P} \text { Loss } \\
\mathrm{T}\end{array}$ & QLoss & & & & & & & & & \\
\hline 1 & kV & & MW & MVar & MW & MNar & & & & & & & & & \\
\hline 1 & 66 & & 0.001 & 0 & 0.201 & 4.34 & & & & & & & & & \\
\hline $\begin{array}{l}1 \\
1\end{array}$ & $\begin{array}{l}220 \\
400\end{array}$ & & $\begin{array}{l}147.32 \\
34.16\end{array}$ & $\begin{array}{l}-1416.8 \\
-879.77\end{array}$ & $\begin{array}{l}29.19^{-} \\
14.843\end{array}$ & $\begin{array}{l}702.31 \\
447.55\end{array}$ & & & & & & & & & \\
\hline 1 & & & & & & & & & & & & & & & \\
\hline 1 & From & To & & & $\mathrm{P} \mathrm{Tie}^{--}$ & QTie & $\begin{array}{l}\mathrm{P} \text { Tie } \\
\text { Sc }\end{array}$ & & & & & & & & \\
\hline 1 & Area/Zone & ArealZone & & & MW & MVar & MW & & & & & & & & \\
\hline 1 & Zone 1 & Zone 2 & & & 1165.9 & -71317 & & & & & & & & & \\
\hline 1 & Zone 2 & Zone 3 & & & -58364 & 579.6 & & & & & & & & & \\
\hline $\begin{array}{l}1 \\
2\end{array}$ & $\begin{array}{l}\text { Zone } 3 \\
\text { Zone } 3\end{array}$ & $\begin{array}{l}\text { Zone } 4 \\
\text { Zone } 5\end{array}$ & & & $\begin{array}{l}951.49 \\
-625.48\end{array}$ & $\begin{array}{l}-508.31 \\
97.72\end{array}$ & & & & & & & & & \\
\hline 2 & & & & & & & & & & & & & & & \\
\hline
\end{tabular}

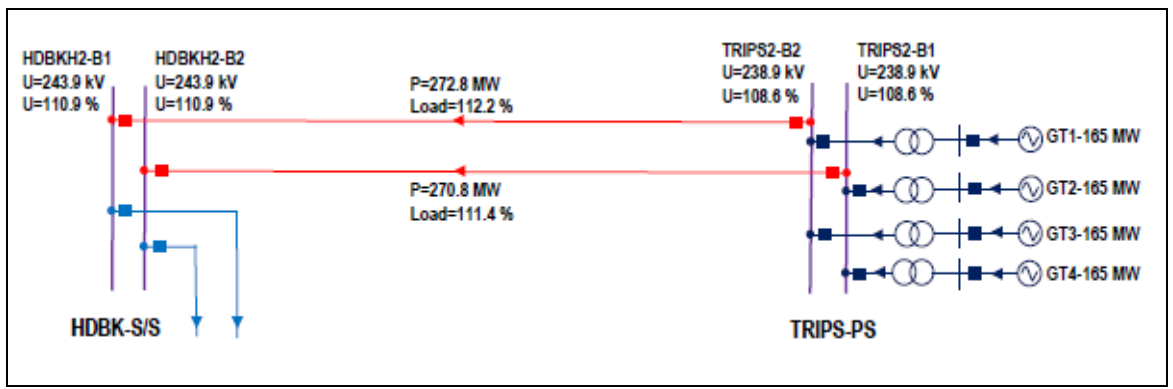

Figure 3. Load flow using ACSR overhead line.

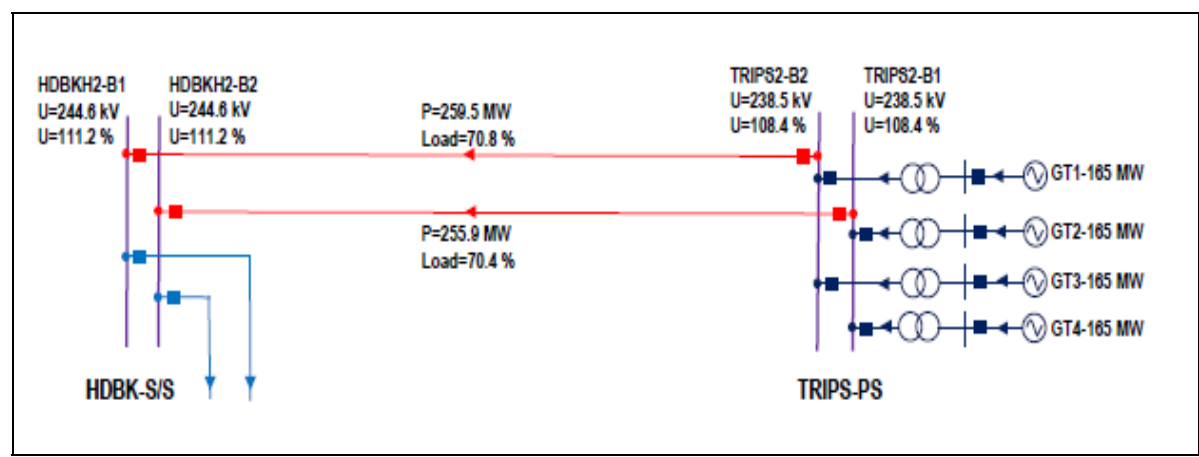

Figure 4. Load flow using GTACSR overhead line.

By considering the Temperature Coefficient of Resistance of $0.004 /{ }^{\circ} \mathrm{C}$ with an average span between towers of $420 \mathrm{~m}$, the assumed current carrying capacity is calculated based on the following weather conditions:
- Ambient Temp:
$40{ }^{\circ} \mathrm{C}$
- Wind Velocity (cross wind):
$0.5 \mathrm{~m} / \mathrm{sec}$
- Solar radiation:
$0.1 \mathrm{~W} / \mathrm{cm}^{2}$
- Emissivity constant:
0.9

The following formula is used: where:

$$
I(a m p)=\sqrt{\frac{\pi \cdot D \cdot k \cdot \theta}{R a c(T+\theta) \cdot 10^{-6}}}
$$

$-D=$ Diameter of conductor

$-k=$ Coefficient of Solar radiation

- $T=$ Ambient Temp

$$
\begin{aligned}
& -\theta=\text { Rate of Temp Rise } \\
& -R_{d c}=\text { DC Resistance at } 20^{\circ} C \\
& -R_{a c}=k \times R_{d c}
\end{aligned}
$$

\section{Simulation results}

- Line Losses:

When modeling the congested transmission line by generating the amount of capacity required at "TWPS" to feed the load center of "HKSS" via the congested line, the results obtained a high losses in the line with its traditional ACSR conductor. When the line conductor is remodeled using GTACSR conductor, the losses on the line was decreased and to very low impedance.

- Line Loading: 
By modeling the transmission line with ACSR, to carry a power of power rated at $272.8 \mathrm{MW}$, the simulation resulted in $112.2 \%$ of loading, whereas, when the line modeled using GTACSR conductor, with the same MW capacity, the percentage load obtained was only $70.8 \%$.

\section{Other concerns}

With the ongoing situation in Libya, concerns have been raised about electricity blackouts which is seen as vital to the country's stability and economy. Several incidents have contributed to these worries, including a power outage in the western and eastern regions and a blackout across the entire country.

With widespread use of superconducting technology grid highway energy consumption can be reduced by 5 $7 \%$, which means an equivalent reduction in $\mathrm{CO} 2$ emissions from electricity generation. But superconductors can also become part of a simplification of the electrical infrastructure. This is because they can transmit massive currents, something which can further be utilized to reduce the number of voltage levels (fewer transformer substations). This has also been feasible in underground transmission in warm and cold environment by utilizing power cables using liquid nitrogen cooling system operating at $\left(-200{ }^{\circ} \mathrm{C}\right)$ [8]. A $500 \mathrm{~m}$ and $1000 \mathrm{~m}$ DC superconducting power cables design projects were started in Chubu University in Japan during 2013 to connect a data centre with DC from large scale array photovoltaic plant. During the design and the construction in the field, a test benches were constructed to investigate the performance of the individual components of the cable system. The design value of the heat leak from the current lead was $35 \mathrm{~W} / \mathrm{kA}$ and the experimental value was $30.5 \mathrm{~W} / \mathrm{kA}$ at the rated current [9]. Thus control of the thermal contraction and expansion are rather important to maintain safety of power cables. Such designs will enable cheaper electricity highways and superconductivity materials may dominate the electric energy transmission in the near future.

\section{Conclusion}

A simulation was made to a congested $220 \mathrm{kV}$ double conductor transmission line to tackle the problem of bottleneck. The obtained results when modeling a superconductor material as the main transmission proved to be the most appropriate option. The solution is recommended to the utility to be implemented as to clear the line congestion from the point-of-view of cost effective, time consuming and using all existing fittings. By using such high temp gap-type superconductors in areas of significant growth in power demand, up to double current carrying capacity can be obtained which will reducing of congested bottlenecks during peak loads and prevent outages of heavy loaded lines. While similar cross section area of the gap-type superconductor to that of original installed ACSR conductors and apart from the compressed connectors and dead-end clamps, all existing insulator strings or posts and transmission tower arrangements such as clevis, extension clevis and yokes can still be used and therefore reduce the overall replacement investment.

\section{References}

1. Mehran Keshavarzian, Charles H. Priebe, "Sag and Tension Calculation for Overhead Transmission Lines at High Temperatures-Modified Ruling Span Method" IEEE Transaction on Power Delivery, Vol. 15, No. 2, (2000)

2. GECOL (General Electric Company of Libya), Updated Power Transmission System Layout, (2013)

3. GECOL (General Electric Company of Libya), Overhead Transmission Line Design Standards, Version 1.0, 2007

4. Superconducting power line to shore up New York grid, " Technical Report" by New Scientist Tech, New York Power Grid Authority, May (2007)

5. J. E Hirsch, "The Origin of the Meissner Effect in New and Old Superconductors", Physical Scripta, 85: 035704, (2012)

6. Rudolf de Bruyn Ouboter, "Heike Kamerlingh Onnes's Discovery of Superconductivity”, Scientific American p 98, March (1997)

7. Brian Wareing, "Types and Uses of High Temperature Conductors", Cigré WG48, AG06 Seminar, Bangkok, Thailand, (2006)

8. Mbunwe Muncho Josephine, Development Trends of Superconducting Cables Technology for Power Transmission Applications, World Congress of Engineering \& Computer Science (WCECS 2015), Vol I, San Francisco, USA, (2015) .

9. S. Yamaguchi, H. Koshizuka, K. Hayashi and T. Sawamura, "Concept and Design of 500m \& 1000m DC Superconducting Power Cables in Ishikari, Japan", IEEE Transactions on Applied Superconductivit, Volume 25, Issue 3, (2015). 